\title{
Material Basis For Combining Euphrobia Kansui And Licorice Based On Rat Liver Microsomal
}

\section{Tingting Wang ( $\nabla 57719874 @ q q . c o m)$}

Hebei University of Chinese Medicine https://orcid.org/0000-0002-6578-5641

\section{Haoyue Li}

Hebei University of Chinese Medicine

\section{Cheng Shi}

Hebei University of Chinese Medicine

Lei Hao

Hebei University of Chinese Medicine

Yanrui Liu

Hebei University of Chinese Medicine

\section{Rui Wang}

Hebei University of Chinese Medicine

\section{Weili Yang}

Hebei University of Chinese Medicine

\section{Xi Wang}

Hebei University of Chinese Medicine

\section{Research Article}

Keywords: Kansui, Licorice, kansuiphorin C, CYP450

Posted Date: December 1st, 2021

DOI: https://doi.org/10.21203/rs.3.rs-1090976/v1

License: (c) (1) This work is licensed under a Creative Commons Attribution 4.0 International License.

Read Full License 


\title{
Material basis for combining Euphrobia kansui and Licorice based on rat liver microsomal
}

Tingting Wang ${ }^{\#}$ Haoyue Li $^{\#}$, Cheng Shi, Lei Hao, Yanrui Liu, Rui Wang, Weili Yang, Xi Wang*,

College of Pharmacy, Heibei University of Chinese Medicine, Shijiazhuang, China

\begin{abstract}
Background: The herbal-pair, Kansui and Licorice, belongs to the "eighteen incompatible medicaments" category of traditional Chinese medicine. Kansuiphorin C (KC) is the main toxic component of Kansui. The main component of licorice is glycyrrhizic acid, which is hydrolyzed to glycyrrhetinic acid. Currently, the synergistic mechanism between Kansui and Licorice is unclear.

Methods: Rat liver microsomes were used in this experiment, HPLC was used to detect the contents of $\mathrm{KC}$, glycyrrhizic acid, and glycyrrhetinic acid to determine whether these compounds are metabolic substrates of CYP450. A control group with isozyme inhibitors was also employed to reveal the isozyme subtypes involved in compound metabolism. To further explain the induction or inhibitory effect of the above compounds on liver microsomal enzymes, enzyme activity was indirectly revealed based on changes in the contents of known metabolites of CYP2E1, CYP2C9, and CYP3A4.
\end{abstract}

Results: KC and glycyrrhetinic acid were metabolic substrates of CYP450. CYP2E1 and CYP2C9 are mainly involved in the partial metabolism of glycyrrhizic acid in the liver. CYP2E1 and CYP3A4 are mainly involved in the partial metabolism of glycyrrhetinic acid in the liver. CYP2E1, CYP2C9, and CYP3A4 did not play a major

\footnotetext{
\# Tingting Wang and Haoyue Li are co-first authors.

* Corresponding author: Xi Wang, Department of clinical Chinese medicine, Collage of pharmacy, Hebei University of Chinese Medicine, Shijiazhuang, China. Email: wxi830205@163.com
} 
role in the metabolism of $\mathrm{KC}$. $\mathrm{KC}$ had little effect on the metabolism of glycyrrhizic acid and glycyrrhetinic acid. Glycyrrhizic acid, glycyrrhetinic acid, and $\mathrm{KC}$ induced CYP3A4 and inhibit CYP2E1. Both glycyrrhizic acid and glycyrrhetinic acid could inhibit the induction of CYP3A4 after combination with $\mathrm{KC}$. $\mathrm{KC}$ with glycyrrhizic acid could synergistically inhibit the activity of CYP2E1, while KC with glycyrrhetinic acid could synergistically induce the activity of CYP2E1

Conclusion: $\mathrm{KC}$ and glycyrrhetinic acid were metabolic substrates of CYP450. KC, glycyrrhizic acid and glycyrrhetinic acid have different inducing and inhibiting effects on CYP450 enzyme.

Keywords: Kansui, Licorice, kansuiphorin C, CYP450

\section{Background}

The eighteen incompatible medicaments are important for explaining the properties of traditional Chinese medicine ${ }^{[1]}$. Based on the traditional Chinese medicine theory, the use of contraindicating drugs will lead to an increase in toxicity and side effects or a decrease in efficacy. As a result, these drugs belong to the incompatibility category of traditional Chinese medicine ${ }^{[2-3]}$. The herbal-pair, Kansui and licorice, belongs to the category of "18 incompatible medicaments" ${ }^{[4]}$. Kansui is the dried root of the euphorbiaceae plant, euphorbia kansui T. N. Liou ex S. B. Hois, a type of markedly purgative water drug ${ }^{[5]}$. The major component of this plant is giant euphorbia officinalis diterpenoids ${ }^{[6-7]}$, which is the main irritant and toxic ingredient. Kansuiphorin $\mathrm{C}(\mathrm{KC})$ is also an ingredient found in kansui ${ }^{[8]}$. Licorice is the dried root and rhizome of the leguminous plant, Glycyrrhiza uralensis Fisch. One of the main components of licorice is glycyrrhizic acid ${ }^{[9-10]}$. Glycyrrhizic acid is hydrolyzed to produce glycyrrhetinic $\operatorname{acid}^{[11]}$. Further, it has a function similar to adrenocortical hormones and can lead to water-sodium retention ${ }^{[12]}$. Therefore, from the viewpoint of water-electrolyte metabolism, the co-administration of Kansui and Licorice should be prohibited owing to their synergistic induction of edema ${ }^{[13]}$. However, the mechanism of Euphorbia kansui and licorice has not been fully studied, thereby markedly 
hindering further development of these compounds.

Cytochrome P450 (CYP450) is the main component of the liver microsomal mixed function oxidase system ${ }^{[14]}$ and is involved in the phase I biotransformation of many endogenous and exogenous compounds in vivo ${ }^{[15]}$. Thus, CYP450 not only reduces the long-term accumulation of drugs in the body and prevents drug accumulation poisoning, but also converts some protoxicants into toxicants, resulting in a toxic effect ${ }^{[16]}$. The P450 enzymes that are involved in the metabolism of most drugs in vivo are mainly composed of three gene families: CYP1, CYP2, and CYP3. Each gene family is known to possess many subtypes ${ }^{[17]}$. Among them, CYP3A4/5, CYP2C9, and CYP2E1 are involved in approximately 96\% of the biotransformation of clinical drugs metabolized by CYP450 enzymes. Further, each subtype has its own metabolic substrate and metabolic mode ${ }^{[18-19]}$.

In this study, HPLC combined with metabolic pathway analysis was used to determine whether KC, glycyrrhetinic acid, and glycyrrhizic acid are metabolic substrates of the CYP450 enzymes and isozyme substrates involved in compound metabolism. We also sought to determine whether kansui and licorice are synergistically metabolized by liver enzymes and play a role in the metabolism of toxic substances or glycyrrhetinic acid. Through metabonomics, studying the interaction between traditional Chinese medicine from the viewpoint of CYP450 enzymes can provide an experimental basis for exploring the mechanism of action of the 18 incompatible medicaments.

\section{Methods}

\subsection{Reagents and chemicals}

NADPH and PBS were purchased from Beijing Solarbio Science and Technology Co., Ltd. (Beijing, China). Rat liver microsomes were purchased from the Research Institute for Liver Disease Co., Ltd. (Shanghai, China). Glycyrrhizic acid, diethyldithiocarbamic acid, phenobarbital, cimetidine, tolbutamide toluenesulfonbutylurea, 4-hydroxytoluenesulfonbutylurea, 6-hydroxychlorzoxazone, and midazolam were purchased from Sigma-Aldrich (St. Louis, MO, USA). 
Glycyrrhetinic acid, KC, phenacetin, benzbromarone, ketoconazole, and chlorzoxazone were purchased from the China Institute for Food and Drug Control (Beijing, China). An ultra-pure water meter was purchased from Beijing Kangming Teke Technology Development Co., Ltd. (Beijing, China). Cortisone acetate was purchased from Shanghai Dibai Biological Technology Co., Ltd. (Shanghai, China, >98\%). Acetonitrile was purchased from Fisher Scientific Co., Ltd. (chromatography-grade, Pure, Pittsburgh, USA). All other reagents were of analytical grade.

\subsection{Solution preparation}

The enzyme inhibitors, amiodarone hydrochloride, diethyldithiocarbamic acid, and ketoconazole were prepared at a concentration of $1 \mathrm{~g} / \mathrm{L}$ using PBS.

KC: KC powder $(1 \mathrm{mg})$ was dissolved in $200 \mu \mathrm{L}$ DMSO. Thereafter, PBS was added to the solution to create a final volume of $1 \mathrm{~mL}$. The reserve liquid was prepared at a concentration of $1 \mathrm{~g} / \mathrm{L}$.

Glycyrrhetinic acid and glycyrrhizic acid: $1 \mathrm{mg}$ glycyrrhetinic acid was weighed and dissolved in heated water to create a final volume of $10 \mathrm{~mL}$; the final concentration of each solution was $100 \mathrm{mg} / \mathrm{L}$. Real-time preparation was carried out. Briefly, the application solution was placed in a hot water bath to maintain its solubility. Glycyrrhizic acid (1 mg) was mixed with $100 \mu \mathrm{L}$ of ethanol. Thereafter, PBS was added to achieve a final volume of $1 \mathrm{~mL}$ and a concentration of $1 \mathrm{~g} / \mathrm{L}$.

\subsection{Liver microsomal incubation system}

The total volume of the incubation system was $200 \mu \mathrm{L}$ and the final concentration of liver microsomal protein was $1 \mathrm{~g} / \mathrm{L}^{[20]}$. For the NADPH regeneration system (containing $0.5 \mathrm{mmol} / \mathrm{L}$ NADP, $10 \mathrm{mmol} / \mathrm{L}$ G-6-P, $1 \mathrm{kU} / \mathrm{L}$ G-6-P-OH, $0.5 \mathrm{mmol} / \mathrm{L}$ $\mathrm{MgCl}_{2}$ ), NADPH was prepared at a concentration of $1 \mathrm{mg} \cdot \mathrm{ml}^{-1}$. The liver microsome was used on ice, stored in liquid nitrogen at $-26{ }^{\circ} \mathrm{C}$, and dissolved at $4{ }^{\circ} \mathrm{C}$ for use ${ }^{[21]}$. 


\section{glycyrrhizic acid in liver microsomes in vitro}

2.4.1 Grouping and Sample preparation

The compounds were divided into group A: $\mathrm{KC}+$ glycyrrhetinic acid + glycyrrhizic acid control group; Group B: KC + liver microsome group, glycyrrhetinic acid + liver microsome group, and glycyrrhizic acid + liver microsome group; Group C: $\mathrm{KC}+$ glycyrrhetinic acid + liver microsome group; Group D: KC + glycyrrhizic acid + liver microsome group; Group E: KC + benzbromarone + liver microsome group, glycyrrhetinic acid + benzbromarone + liver microsome group, glycyrrhizic acid + benzbromarone + liver microsome group; Group F: KC + diethyldithiocarbamic acid + liver microsome group, glycyrrhetinic acid + diethyldithiocarbamic acid + liver microsome group, and glycyrrhizic acid + diethyldithiocarbamic acid +liver microsome group; and Group G: $\mathrm{KC}+$ ketoconazole + liver microsome group, glycyrrhetinic acid + ketoconazole + liver microsome group, and glycyrrhizic acid + ketoconazole + liver microsome group.

In the enzyme inhibitor groups, the enzyme inhibitors amiodarone hydrochloride, diethyldithiocarbamic acid, and ketoconazole were separately added to the liver microsomal incubation system and incubated at $37{ }^{\circ} \mathrm{C}$ for $5 \mathrm{~min}$. Other controls were incubated at $37{ }^{\circ} \mathrm{C}$ for $5 \mathrm{~min}$. The corresponding compounds were added to start the reaction. After incubation at $37{ }^{\circ} \mathrm{C}$ for $30 \mathrm{~min}, 50 \mu \mathrm{L}$ of ice-cold acetonitrile was added to stop the reaction. The homogenate was centrifuged at 12000 rpm for 12 min at $4{ }^{\circ} \mathrm{C}$, and the supernatant was injected into the system for HPLC analysis.

\subsubsection{HPLC conditions}

The Agilent 1100 HPLC system was employed. This system was equipped with a degasser, binary pump, auto-sampler, and Zorbax Eclipse Plus-C18 $(250 \times 4.6 \mathrm{~mm}, 5$ $\mu \mathrm{m})$. The analytical column was maintained at $38{ }^{\circ} \mathrm{C}$ and the mobile phase was composed of water (A) and acetonitrile (D). The gradient program for glycyrrhetinic acid and glycyrrhizic acid was: 0 min, 10\% D; $13.25 \mathrm{~min}, 40 \%$ D; $20.45 \mathrm{~min}, 60 \% \mathrm{D}$; $38.0 \mathrm{~min}, 90 \% \mathrm{D} ; 40 \mathrm{~min}, 10 \% \mathrm{D}$; and return to the initial condition for $2 \mathrm{~min}$. The 
detection wavelength was $250 \mathrm{~nm}$. The following gradient program was used for KC: $0 \min , 75 \% \mathrm{D} ; 15 \min , 75 \% \mathrm{D} ; 18 \mathrm{~min}, 100 \% \mathrm{D} ; 20 \mathrm{~min}, 75 \% \mathrm{D}$; and return to the initial condition for $5 \mathrm{~min}$. The detection wavelength was $235 \mathrm{~nm}$, the flow rate was 1 $\mathrm{mL} / \mathrm{min}$, and the injection volume was $10 \mu \mathrm{L}$. Three parallel tubes were prepared for each isozyme. To ensure consistent performance of the analytical system, the reference substances $500 \mu \mathrm{g} / \mathrm{mL} \mathrm{KC}$, glycyrrhizic acid, and glycyrrhetinic acid were repeatedly injected six times to determine the precision during the operation of the instrument.

\subsection{Effects of KC, glycyrrhetinic acid, and glycyrrhizic acid on liver microsomal CYP450 isozymes}

2.5.1 Grouping and Sample preparation

The following groups were employed: Group A: metabolic substrate group; Group B: liver microsome + metabolic substrate; Group C: liver microsome + phenobarbital (enzyme inducer) + metabolic substrate; Group D: liver microsome + cimetidine (enzyme inhibitor) + metabolic substrate; Group E: liver microsome + glycyrrhizic acid + metabolic substrate; Group F: liver microsome + glycyrrhetinic acid + metabolic substrate; Group G: liver microsome + KC + metabolic substrate; Group H: liver microsome $+\mathrm{KC}+$ glycyrrhizic acid + metabolic substrate; and Group I: liver microsome $+\mathrm{KC}+$ glycyrrhetinic acid + metabolic substrate .

The drug to be tested (or blank solvent), $10 \mathrm{mmol} / \mathrm{L} \mathrm{MgCl}_{2}$, and $\mathrm{pH} 7.4$ phosphate buffer were added to the group of liver microsomes containing probe drugs, pre-incubated, and oscillated in a water bath at $37{ }^{\circ} \mathrm{C}$. Thereafter, $10 \mathrm{mmol} / \mathrm{L}$ NADPH was added to start the reaction with a total reaction volume of $150 \mu \mathrm{L}$.

Detection of CYP2E1 enzyme activity: The following reagents were dissolved in water: NADPH $4 \mathrm{mg} / \mathrm{mL}$, chlorzoxazone $100 \mu \mathrm{g} / \mathrm{mL}$, phenacetin $50 \mu \mathrm{g} / \mathrm{mL}$, phenobarbital $50 \mu \mathrm{g} / \mathrm{mL}$, cimetidine $50 \mu \mathrm{g} / \mathrm{mL}$, glycyrrhizic acid $50 \mu \mathrm{g} / \mathrm{mL}$, glycyrrhetinic acid $50 \mu \mathrm{g} / \mathrm{mL}$, and $\mathrm{KC} 50 \mu \mathrm{g} / \mathrm{mL}$.

A total of $40 \mu \mathrm{L}$ NADPH and $30 \mu \mathrm{L}$ of rat liver microsomal were added to a $37{ }^{\circ} \mathrm{C}$ water bath for $5 \mathrm{~min}$ to start the reaction, before being placed on ice. Thereafter, 
$20 \mu \mathrm{L}$ chlorzoxazone, $20 \mu \mathrm{L}$ experimental drugs, and $40 \mu \mathrm{L}$ PBS were added to the $37{ }^{\circ} \mathrm{C}$ water bath for $60 \mathrm{~min}$. Ice-cold acetonitrile was added to terminate the reaction. Phenacetin $(20 \mu \mathrm{L})$ was employed as the internal standard, shaken for $15 \mathrm{~s}$, ultrasonicated for $15 \mathrm{~s}$, and centrifuged at $12000 \mathrm{rpm}$ for $30 \mathrm{~min}$ at $4{ }^{\circ} \mathrm{C}$. The supernatant was retrieved to determine the content of 6-hydroxychlorzoxazone.

Detection of CYP2C9 enzyme activity: The following reagents were dissolved in water: NADPH $4 \mathrm{mg} / \mathrm{mL}$, toluenesulfonbutylurea $1 \mathrm{mg} / \mathrm{mL}$, phenacetin $1 \mathrm{mg} / \mathrm{mL}$, phenobarbital $1 \mathrm{mg} / \mathrm{mL}$, cimetidine $1 \mathrm{mg} / \mathrm{mL}$, glycyrrhizic acid $1 \mathrm{mg} / \mathrm{mL}$, glycyrrhetinic acid $1 \mathrm{mg} / \mathrm{mL}$, and $\mathrm{KC} 1 \mathrm{mg} / \mathrm{mL}$.

A total of $40 \mu \mathrm{L}$ NADPH and $30 \mu \mathrm{L}$ of rat liver microsomal were added to a $37^{\circ} \mathrm{C}$ water bath for $5 \mathrm{~min}$ to start the reaction, before placement on ice. Subsequently, $20 \mu \mathrm{L}$ toluenesulfonbutylurea, $20 \mu \mathrm{L}$ experimental drugs, and $40 \mu \mathrm{L}$ PBS were added to a $37{ }^{\circ} \mathrm{C}$ water bath for $60 \mathrm{~min}$. Ice-cold acetonitrile was used to terminate the reaction. Phenacetin $(20 \mu \mathrm{L})$ was added as the internal standard, shaken for $15 \mathrm{~s}$, ultrasonicated for $15 \mathrm{~s}$, and centrifuged at $12000 \mathrm{rpm}$ for $30 \mathrm{~min}$ at $4{ }^{\circ} \mathrm{C}$. The supernatant was collected to determine the content of 4-hydroxytoluenesulfonbutylurea.

Detection of CYP3A4 enzyme activity: The following reagents were dissolved in water: NADPH $4 \mathrm{mg} / \mathrm{mL}$, midazolam $100 \mu \mathrm{g} / \mathrm{mL}$, cortisone acetate $50 \mu \mathrm{g} / \mathrm{mL}$, phenobarbital $50 \mu \mathrm{g} / \mathrm{mL}$, cimetidine $50 \mu \mathrm{g} / \mathrm{mL}$, glycyrrhizic acid $50 \mu \mathrm{g} / \mathrm{mL}$, glycyrrhetinic acid $50 \mu \mathrm{g} / \mathrm{mL}$, and $\mathrm{KC} 50 \mu \mathrm{g} / \mathrm{mL}$.

A total of $40 \mu \mathrm{L}$ NADPH and $30 \mu \mathrm{L}$ of rat liver microsomal were added to a $37{ }^{\circ} \mathrm{C}$ water bath for $5 \mathrm{~min}$ to start the reaction, before placement on ice. Thereafter, $20 \mu \mathrm{L}$ midazolam, $20 \mu \mathrm{L}$ experimental drugs, and $40 \mu \mathrm{L}$ PBS were added to a $37{ }^{\circ} \mathrm{C}$ water bath for $60 \mathrm{~min}$, and ice-cold acetonitrile was added to terminate the reaction. Cortisone acetate $(20 \mu \mathrm{L})$ was added as the internal standard, shaken for $15 \mathrm{~s}$, ultrasonicated for $15 \mathrm{~s}$, and centrifuged at $12000 \mathrm{rpm}$ for $30 \mathrm{~min}$ at $4{ }^{\circ} \mathrm{C}$. The supernatant was retrieved to determine the content of 1-hydroxymidazolam. 
The analytical column was maintained at $25^{\circ} \mathrm{C}$, and the mobile phase was composed of water (A) and acetonitrile (D). The following gradient program was employed : 0 min, 37\%-75\% D; $10 \mathrm{~min}, 75 \%-37 \% \mathrm{D} ; 12 \mathrm{~min}, 37 \% \mathrm{D} ; 13 \mathrm{~min}, 37 \% \mathrm{D}$; and return to the initial condition for $3 \mathrm{~min}$. The flow rate was $1 \mathrm{~mL} / \mathrm{min}$ and the injection volume was $10 \mu \mathrm{L}$. Detection was carried out at a wavelength of $280 \mathrm{~nm}$.

\subsubsection{4-hydroxytoluenesulfonbutylurea HPLC conditions}

The analytical column was maintained at $40{ }^{\circ} \mathrm{C}$, and the mobile phase was composed of water (A) and acetonitrile (D). The following gradient program was employed: 0 $\min , 5 \%-60 \% \mathrm{D} ; 20 \mathrm{~min}, 60 \%-5 \% \mathrm{D} ; 25 \mathrm{~min}, 60 \%-5 \% \mathrm{D}$; return to the initial condition in $3 \mathrm{~min}$. The flow rate was $1 \mathrm{~mL} / \mathrm{min}$ and the injection volume was $10 \mu \mathrm{L}$. Detection was carried out at a wavelength of $230 \mathrm{~nm}$.

\subsubsection{1-hydroxymidazolam HPLC conditions}

The analytical column was maintained at $35^{\circ} \mathrm{C}$, and the mobile phase was composed of water (A) and methanol (D). The following gradient program was employed: 0 min, $40 \%-60 \% \mathrm{D} ; 11 \mathrm{~min}, 60 \%-40 \% \mathrm{D} ; 12 \mathrm{~min}, 40 \%-40 \% \mathrm{D} ; 16 \mathrm{~min}, 40 \%$; return to the initial conditions for $3 \mathrm{~min}$. The flow rate was $1 \mathrm{~mL} / \mathrm{min}$ and the injection volume was $10 \mu \mathrm{L}$. Detection was carried out at a wavelength of $240 \mathrm{~nm}$.

\section{RESULTS}

3.1 Effects of CYP450 isozymes on the contents of $\mathrm{KC}$, glycyrrhetinic acid, and glycyrrhizic acid in rat liver microsomes

After the addition of liver microsomes, the content of $\mathrm{KC}$ and glycyrrhetinic acid decreased by $50 \%$, while that of glycyrrhetinic acid decreased by only $16 \%$ under the same conditions.

To further explore the metabolic enzyme subtypes of the three compounds, the corresponding inhibitors of CYP2E1, CYP2C9, and CYP3A4 were added to the liver microsome system. The content of glycyrrhizic acid and glycyrrhetinic acid increased after the addition of enzyme inhibitors. However, the content of glycyrrhizic acid was 
close to that of the control group after the addition of the CYP2E1 inhibitor, suggesting that CYP2E1 is mainly involved in the partial metabolism of glycyrrhizic acid in the liver. Glycyrrhizic acid content increased after the addition of the CYP2C9 inhibitor, indicating that CYP2C9 was also involved in the metabolism of glycyrrhizic acid in the liver. Further, the content of glycyrrhizic acid increased slightly after the addition of CYP3A4 inhibitor, suggesting that CYP3A4 was less involved in the metabolism of glycyrrhizic acid in the liver. As the content of glycyrrhetinic acid increased significantly after the addition of the CYP3A4 and CYP2E1 inhibitors, these inhibitors were found to be mainly involved in the metabolism of glycyrrhetinic acid, while CYP2C9 had less effect on the metabolism of glycyrrhetinic acid. After the addition of $\mathrm{KC}$, the content of glycyrrhizic acid increased slightly, while that of glycyrrhetinic acid decreased slightly; however, the change was not obvious, suggesting that $\mathrm{KC}$ had little effect on the metabolism of glycyrrhizic acid and glycyrrhetinic acid (Table 1, Figures 1-4).

Table 1 The content of KC, glycyrrhizic acid, and glycyrrhetinic acid in the different groups (A G)

\begin{tabular}{cccc}
\hline Group & $\begin{array}{c}\text { KC } \\
(\boldsymbol{\mu g} / \mathbf{m L})\end{array}$ & $\begin{array}{c}\text { Glycyrrhizic acid } \\
(\boldsymbol{\mu g} / \mathbf{m L})\end{array}$ & $\begin{array}{c}\text { Glycyrrhetinic acid } \\
(\boldsymbol{\mu g} / \mathbf{m L})\end{array}$ \\
\hline A & 36.17 & 49.67 & 22.79 \\
B & 18.19 & 41.68 & 11.01 \\
C & 10.71 & 43.86 & - \\
D & 9.68 & - & 10.65 \\
E & 0 & 45.61 & 12.53 \\
F & 11.33 & 47.15 & 15.08 \\
G & 13.72 & 43.94 & 16.06 \\
\hline
\end{tabular}

The content of $\mathrm{KC}$ decreased after the addition of the inhibitors, glycyrrhizic acid, and glycyrrhetinic acid, suggesting that CYP2E1, CYP2C9, and CYP3A4 did not play a major role in the metabolism of KC. Further, no substance was detected after the addition of the inhibitors of CYP2C9. After three inhibitors were added to $\mathrm{KC}$ without liver microsomes, the content of $\mathrm{KC}$ decreased. $\mathrm{KC}$ reacted with three inhibitors, and glycyrrhizic acid and glycyrrhetinic acid promoted the metabolism of 
KC (Table 2).

Table 2 Effects of benzbromarone, diethyldithiocarbiamic acid, and ketoconazole on KC content.

\begin{tabular}{cc}
\hline Group & $\mathbf{K C}(\boldsymbol{\mu g} / \mathbf{m L})$ \\
\hline KC & 77.08 \\
KC + Benzbromarone & 66.09 \\
KC+ diethyldithiocarbamic acid & 70.18 \\
KC+ ketoconazole & 63.50 \\
\hline
\end{tabular}

\subsection{Effects of KC, glycyrrhetinic acid, and glycyrrhizic acid on CYP450 isozymes} in rat liver microsomes

Phenobarbital induced CYP2C9 while cimetidine inhibited CYP2E1. Glycyrrhizic acid, glycyrrhetinic acid, and $\mathrm{KC}$ induced CYP3A4, with $\mathrm{KC}$ causing the strongest induction. Glycyrrhizic acid, glycyrrhetinic acid, and $\mathrm{KC}$ had similar inhibitory effects on CYP2E1, whereas the effects of glycyrrhizic acid, glycyrrhetinic acid, and $\mathrm{KC}$, and their compatibility with CYP2C9 were not obvious. The content of 1-hydroxymidazolam in $\mathrm{KC}$ combined with glycyrrhizic acid and glycyrrhetinic acid was lower than that in the $\mathrm{KC}$ group, suggesting that both glycyrrhizic acid and glycyrrhetinic acid could inhibit the induction of CYP3A4 after combination with KC. $\mathrm{KC}$ with glycyrrhizic acid could synergistically inhibit the activity of CYP2E1, while KC with glycyrrhetinic acid could synergistically induce the activity of CYP2E1 (Table 3, Figures 5-8).

Table 3 The activity of CYP3A4, CYP2C9, and CYP2E1 in the different groups (A-I)

\begin{tabular}{cccc}
\hline group & $\begin{array}{r}\text { 1-hydroxymidazolam } \\
(\mathbf{m g} / \mathbf{m L})\end{array}$ & $\begin{array}{c}\text { 4-hydroxytoluenesulfonylurea } \\
(\mathbf{m g} / \mathbf{m L})\end{array}$ & $\begin{array}{c}\text { 6-hydroxychlorzoxazone } \\
(\mathbf{m g} / \mathbf{m L})\end{array}$ \\
\hline A & 171.623 & 94.385 & 121.751 \\
B & 243.831 & 100.189 & 167.973 \\
C & 241.521 & 140.653 & 148.437 \\
D & 258.032 & 99.950 & 145.870 \\
E & 254.361 & 103.056 & 146.161 \\
F & 262.700 & 101.071 & 146.947 \\
G & 294.922 & 104.284 & 146.620 \\
H & 250.661 & 100.897 & 133.564 \\
\hline
\end{tabular}




\begin{tabular}{ccccccc}
\hline \multicolumn{2}{c}{265.1963} & & \multicolumn{2}{c}{96.397} & \multicolumn{2}{c}{150.870} \\
\hline (Toluenesulfonylurea is the metabolic & substrate of & CYP2C9 & while
\end{tabular}
4-hydroxytoluenesulfonylurea is the metabolite. Midazolam is the metabolic substrate of CYP3A4 while 1-hydroxymidazolam is the metabolite; and chlorzoxazone is the metabolic substrate of CYP2E1 while 6-hydroxychlorzoxazone is the metabolite.)

\section{DISCUSSION}

The processes of metabolism and transformation of drugs in the body are complex. Although the components of traditional Chinese medicine are complex, in the final analysis, the basic of its function is still the interaction between compounds of traditional Chinese medicine, and the metabolism of its effective components in the body still follows the basic law of general drug metabolism.

\subsection{Function of subtypes of liver drug enzymes}

CYP3A4 is one of the most important drug metabolic enzymes in the liver ${ }^{[22]}$ that participates in the metabolism of approximately $45 \%$ to $60 \%$ of drugs commonly used in clinics. However, the metabolism of drugs markedly varies among individuals (i.e., approximately 10-100 times in the liver and 30 times in the small intestine) ${ }^{[23]}$.

CYP2E1 is a key member of the CYP450 enzyme system and a key enzyme involved in the metabolism and inactivation of drugs and some toxic substances (ethanol, acetone, benzene, carbon tetrachloride, etc.) ${ }^{[24-25]}$. CYP2E1 is genetically polymorphic, which can affect its expression and lead to differences in drug metabolism and toxicity among individuals; this is crucial for the active transformation of drugs and poisons ${ }^{[26]}$. Previous studies have shown that the combination of kansui and licorice can induce the gene and protein expression of CYP2E1 to a greater extent, and promote the transformation of its pre-carcinogens and pre-toxicants into carcinogens and toxicants ${ }^{[27]}$.

The CYP2C family is the largest subfamily of CYP450 enzymes in mammals. CYP2C9 is the main member of the family, accounting for $20 \%$ of the total liver microparticle CYP450 enzymes, and approximately $16 \%$ of commonly used clinical drugs are catalyzed by this enzyme ${ }^{[28-29]}$. CYP2C9 gene polymorphisms are an 
important risk factor for hepatotoxicity. The high mutation rates of CYP2C9*2 and CYP2C9*3 mutants reduce the metabolic rate of CYP2C9 for drugs by tens of times, thereby markedly changing the clearance rate of drugs in the body, resulting in drug accumulation, and a 7.50-fold increase in the risk of liver injury ${ }^{[30]}$.

Many subtypes of liver drug enzymes have been demonstrated to play the role of drug metabolizer, promoting the transformation of inactive substances into biologically active substances, degrading biotoxicants, and promoting the transformation of pre-toxicants or pre-carcinogens into carcinogens or poisons.

\subsection{Effect of CYP450 on the contents of glycyrrhizic acid, glycyrrhetinic acid, and $\mathrm{KC}$}

Based on the results presented in 3.1, when glycyrrhizic acid and glycyrrhetinic acid were combined with $\mathrm{KC}$, the content of glycyrrhizic acid increased slightly, while that of glycyrrhetinic acid decreased slightly. However, such change was not obvious, suggesting that $\mathrm{KC}$ had little effect on the metabolism of glycyrrhizic acid and glycyrrhetinic acid. Based on these findings, including those of metabonomics, there may be other substances in Fructus kansui that promote the metabolism of glycyrrhetinic acid. KC and glycyrrhetinic acid are suggested to be the metabolic substrates of liver drug enzymes. Further, the main metabolic pathway of glycyrrhizic acid is not liver microsome enzymes.

\subsection{Subtypes of liver drug enzymes involved in glycyrrhizic acid, glycyrrhetinic acid, and KC metabolism}

Liver microsomal experiments in vitro showed that glycyrrhetinic acid was less metabolized in the liver, and glycyrrhetinic acid was mainly metabolized through CYP3A4 and CYP2E1. Although KC is the metabolic substrate of liver microsomal enzymes, it may not be metabolized by CYP2C9, CYP3A1, and CYP2E1, as well as other metabolic subtypes. Some researchers believe that CYP2C19 may be involved in the metabolism of $\mathrm{KA}$ and $\mathrm{KB}$, which are toxic components of kansui. KA, KB, and $\mathrm{KC}$ are terpenoids of Euphorbia kansui; thus, $\mathrm{KC}$ may also be metabolized by 
CYP2C19 ${ }^{[31]}$. The combination of glycyrrhizic acid and glycyrrhetinic acid with KC enhanced the metabolism of KC, inhibited the metabolism of glycyrrhizic acid, and promoted the metabolism of glycyrrhetinic acid. However, studies have shown that glycyrrhizic acid and glycyrrhetinic acid can inhibit the metabolism of $\mathrm{KA}$ and $\mathrm{KB}^{[32]}$; thus, it is necessary to combine the content, absorption, and distribution of three terpenoid esters in Fructus kansui to further reveal the synergistic mechanism.

The enzyme activity experiment revealed that glycyrrhizic acid, glycyrrhetinic acid, and $\mathrm{KC}$ could induce CYP3A4, with KC exerting the strongest inducing effect. The content of 1-hydroxymidazolam in the $\mathrm{KC}$ group with glycyrrhizic acid and glycyrrhetinic acid was lower than that in the $\mathrm{KC}$ group, but was similar to glycyrrhizic acid group and glycyrrhetinic acid group. Such findings suggest that the combination of glycyrrhizic acid and glycyrrhetinic acid inhibited the induction of CYP3A4 by $\mathrm{KC}$, which may be related to the promotion of $\mathrm{KC}$ metabolism due to the combination of glycyrrhizic acid and glycyrrhetinic acid. The induction of CYP3A4 decreased due to a decrease in $\mathrm{KC}$ content, which showed an inhibitory effect. Glycyrrhizic acid, glycyrrhetinic acid, and KC had inhibitory effects on CYP2E1, and their degree of inhibition was similar. The compatibility of $\mathrm{KC}$ with glycyrrhetinic acid induced CYP2E1 activity, while its compatibility with glycyrrhizic acid inhibited the activity of CYP2E1. The analysis may be related to their combination in promoting $\mathrm{KC}$ metabolism, inhibiting glycyrrhizic acid metabolism, and promoting glycyrrhetinic acid metabolism. Although the inhibitory effect of the three were similar, that of glycyrrhizic acid was relatively stronger. Accordingly, the content of $\mathrm{KC}$ decreased and the content of glycyrrhetinic acid increased, thereby displaying an inhibitory effect. In contrast, the contents of $\mathrm{KC}$ and glycyrrhetinic acid decreased; thus, the inhibition of CYP2E1 decreased under the same conditions, which led to an increase in metabolites and resulted in the induction effect.

Based on the literature summary, the efficacy and toxicity of the combination of kansui with licorice are affected by dosage, proportion, mode of administration, variety of processing, route of administration, administration time, etc. ${ }^{[33-37]}$. Among them, there have been many studies on compatible doses and proportion ${ }^{[38-39]}$. When 
the ratio of kansui and licorice is 1: 15 or 1: 10 based on the low dose (close to the clinical dosage), licorice not only plays a role in diuresis, but can also reduce toxicity to a certain extent ${ }^{[40]}$.

From the point of view of drug metabolic enzymes, to study the biological effects of the synergy between Fructus kansui and licorice, our findings not only provide a reference for the security of drug usage in clinical practice, but also serve as a useful reference for exploring the mechanism of compatibility of traditional Chinese medicine and expanding this research idea.

\section{CONCLUSIONS}

Through in vitro liver microsomal experiments, $\mathrm{KC}$ and glycyrrhetinic acid were identified as the metabolic substrates of liver microsomal enzymes.

The main subtypes involved in glycyrrhetinic acid metabolism are CYP3A4 and CYP2E1. CYP2E1, CYP2C9, and CYP3A4 do not play a major role in the metabolism of KC. Herein, glycyrrhizic acid, glycyrrhetinic acid, and KC induced effects on CYP3A4, with $\mathrm{KC}$ exhibiting the strongest effect. When combined with $\mathrm{KC}$ and glycyrrhizic acid and combined with $\mathrm{KC}$ and glycyrrhetinic acid can inhibit the induction of CYP3A4 by KC. Glycyrrhizic acid, glycyrrhetinic acid, and KC had inhibitory effects on CYP2E1. Further, the degree of inhibition was similar, and the synergism between KC and glycyrrhizic acid could inhibit the activity of CYP2E1, while that between $\mathrm{KC}$ and glycyrrhetinic acid could induce the activity of CYP2E1. The synergistic effects of glycyrrhizic acid, glycyrrhetinic acid, and $\mathrm{KC}$ and their compatibility with CYP2C9 were not obvious.

Based on the compatibility assessment of kansui and licorice, they exhibit both attenuation and synergistic effects, whether by inducing the activity of CYP3A4, inhibiting the activity of CYP2E1, promoting drug metabolism, and inhibiting the transformation of pre-toxicant into toxicant to play an attenuating role still needs futher experimental verification. In the drug interaction, the metabolism of the liver microsomal enzyme to the drug is the first occurrence and is followed by the induction or inhibition of the drug to the liver microsomal enzyme. 


\section{Abbreviationg}

KC: Kansuiphorin C; KA: Kansuiphorin A; KB: Kansuiphorin B; CYP450: Cytochrome P450.

\section{Ethics approval and consent to participate}

The experiment was reviewed by the ethics Committee of Hebei University of Traditional Chinese Medicine

\section{Consent for publication}

Not applicable

\section{Availability of data and materials}

The datasets used and/or analysed during the current study are availiable from the corresponding author on reasonable request.

\section{Competing interests}

The authors declare ehat they have no competing interests.

\section{Funding}

The study was supported by the Youth Foundation of the National Natural Science Foundation of China (No. 81503268), the Youth Top Program of colleges and universities in Hebei Province Science and Technology Research Project (No. BJ2016038), the Central Finance Public Health Project 2017, and the General Survey of Traditional Chinese Medicine Resources (No. Z135080000022).

\section{Author's contributions}

Funding and research design: Xi Wang, Lei Hao, Cheng Shi. Data plotting and HPLC validation experiments: Tingting Wang, Haoyue Li. Writing and statistic: Tingting Wang, Haoyue Li, Yanrui Liu. Experiments: Tingting Wang, Haoyue Li, Rui Wang, Weili Yang.

\section{Acknowledgements}


Not applicable.

\section{Author details}

All the authors are from College of Pharmacy, Heibei University of Chinese Medicine, Shijiazhuang, China.

\section{References}

1. Sun, F.J., Huang, Y.Y., Li, L.L., Yang, C., Zhuang, P.W., Zhang, Y.J. \& Bastos, J.K. Fuzi and Banxia Combination, Eighteen Antagonisms in Chinese Medicine, Aggravates Adriamycin-Induced Cardiomyopathy Associated with PKA/ $\beta 2$ AR-Gs Signaling. Evidence-Based Complementary and Alternative Medicine, 2018. https://doi.org/10.1155/2018/2875873.

2. Ju, L., Li, R.C., \& Li, F. Review of eighteen incompatible medicaments. Shandong Journal of Animal Science and Veterinary Medicine. 2016;37(06),

69-71. https://doi.org/CNKI:SUN:DCMY.0.2016-06-046.

3. Sang, P.P., Hwa, K.O., Hoon, L.G., Suk, L.K., Won, S.D., \& Yeul, K.D. A Study of Eighteen Incompatible Medicaments. Herbal Formula Science. 2006;14(2).

4. Duan, X.J., Wang, J.C., Ye, H., Liu, P., \& Wang, P.F. The study was based on the composition of toxic effect which was by the compatibility of eighteen incompatible medicaments of licorice with euphorbia and Gan Sui Ban Xia decoction. Lishizhen Medicine and Materia Medica

Research. 2018;29(04), 
849-851. https://doi.org/CNKI:SUN:SZGY.0.2018-04-026.

5. Zhang, Y., Cui, Y., Wang, J.R., Zhao, Y.L., \& Yu, Z.G. Metabonomics of incompatible herb pair GansuiGancao based on UHPLC-FT-ICR-MS. Journal of Shenyang Pharmaceutical University. 2020;37(10), 908-912. https://doi.org/10.14066/j.cnki.cn21-1349/r.2020.10.008.

6. Wang, S.Y., Li, J.C., Liu, D., Yang, T., Chen, X.Q., \& Li, R.T. Ingenane and jatrophane-type diterpenoids from Euphorbia kansui with multidrug resistance reversal activity. Phytochemistry. 2021;188. https://doi.org/10.1016/J.PHYTOCHEM.2021.112775.

7. Chen, Y., Luo, D., Chen N.Y., Zhang, Y., Liang, D.E., Zhan, Z.J., \& Ma, L.F. New ingenane diterpenoids from Euphorbia kansui reverse multi-drug resistance. Phytochemistry Letters. 2021;43. https://doi.org/10.1016/J.PHYTOL.2021.03.023.

8. Zhao, X.Y., Cai, X., \& Hu, Z.H. Research progress on biology, chemical constituents in Euphorbia kansui, and their pharmacological effects. Chinese Traditional and Herbal Drugs. $2014 ; 45(20)$

3029-3033. https://doi.org/CNKI:SUN:ZCYO.0.2014-20-032.

9. Tucker, I.M., Burley, A., Petkova, R.E., Hosking, S.L., Penfold, J., Thomas, R.K., Li, P.X., Webster, J.R.P., Welbourn, R., \& Doutch, J. Adsorption and self-assembly properties of the plant based 
biosurfactant, Glycyrrhizic acid. Journal of Colloid And Interface Science.2021; 598. https://doi.org/10.1016/J.JCIS.2021.03.101.

10. Bai, J.W., Xu, J.X., Hang, K., Kuang, Z.H., Ying, L., Zhou, C.W., Ni, L.C., Wang, Y.B., \& Xue, D.T. Glycyrrhizic Acid Promotes Osteogenic Differentiation of Human Bone Marrow Stromal Cells by Activating the Wnt/ $\beta$-Catenin Signaling Pathway. Frontiers in Pharmacology. 2021. https://doi.org/10.3389/FPHAR.2021.607635.

11. Song, W., Zheng, W., Zhang, J., Liu, S.C., Yu, L.Y., \& Ma, B.P. Metabolism of saponins from traditiongal Chinese medicines: a review. Acta Pharmaceutica Sinica. 2018;53(10), 1609-1619. https://doi.org/10.16438/j.0513-4870.2018-0470.

12. Jiang, X., Sun, S.F., Wang, Y., \& Ren, J.J. Research progress on pharmacological effects of Licorice. Chemical Industry Times. 2017;31(07)

25-28. https://doi.org/10.16597/j.cnki.issn.1002-154x.2017.07.007.

13. Shen, J., Kai, J., Tang, Y.P., Zhang, L., Su, S.L., \& Duan, J.A. The Chemical and Biological Properties of Euphorbia kansui. The American Journal of Chinese medicine. 2016;44(2). https://doi.org/10.1142/S0192415X16500154.

14. Guengerich, F.P., Waterman, M.R., Egli, M. Recent Structural Insights into Cytochrome P450 Function. Trends in Pharmacological Sciences. 2016;37(8). https://doi.org/10.1016/j.tips.2016.05.006. 
15. Wang, H., Xia, B.Y., Lin, M., Wang, Y.P., Sun, B., \& Li, Y.Z. Succinic acid inhibits the activity of cytochrome P450 (CYP450) enzymes. Pharmaceutical biology. 2020;58(1). https://doi.org/10.1080/13880209.2020.1839110.

16. Song, Z., Gao, X., Wu, M., Lu, F.P., \& Qin, H.M. Advances in research on structure, function and application of cytochrome P450 enzyme. Microbiology $\quad$ China. 2020;47(07), 2245-2254. https://doi.org/10.13344/j.microbiol.china.200302.

17. Davis, D., Bansal, A., Hassman, D., Akinlade, B., Li, M., Li, Z.Y., Swanson, B., Hamilton, J.D. \& DiCioccio, A.T. Evaluation of Potential Disease - Mediated Drug-Drug Interaction in Patients With Moderate - to - Severe Atopic Dermatitis Receiving Dupilumab. Clinical Pharmacology \& Therapeutics. 2018;104(6). https://doi.org/10.1002/cpt.1058.

18. Zhang, H.F., Wang, Y.P., \& Li, Y. Research development of cytochrome P450. Journal of Jilin Medical University. 2005;(03), 174-177. https://doi.org/CNKI:SUN:JLDS.0.2005-03-022.

19. Zhang, Q., Qu, Z.q., Zhou, Y.q., Zhou, J., Yang, J.W., Li, S.J., Xu, Q.P., \& Zhou, X.D. In vitro study on the effect of cornin on the activity of cytochrome P450 enzymes. BMC complementary medicine and therapies. 2021;21(1). https://doi.org/10.1186/S12906-021-03309-Y. 
20. Sun, Y., He, M.Y., Sun, Y.L., \& Wei, J.H. 4-O-galloylalbiflorin inhibits the activity of CYP3A, 2C9, and 2D in human liver microsomes. Xenobiotica; the fate of foreign compounds in biological systems. 2021;11-19. https://doi.org/10.1080/00498254.2021.1936688.

21. Mieszkowska, A., Hemine, K., Skwierawska, A., Augustin, E., \& Mazerska, Z. Detoxification of the tricyclic antidepressant opipramol and its analog - IS-noh by UGT enzymes before and after activation by phase I enzymes in rat liver microsomes. Chemical Papers. 2021;1-6. https://doi.org/ 10.1007/S11696-021-01647-2.

22. Mondal, S., Ghosh, P., Biswas, D., \& Roy, P.K. Effect of Alcohol Consumption during Antiretroviral Therapy on HIV-1 Replication: Role of Cytochrome P3A4 Enzyme. International Journal of Mathematical, Engineering and Management Sciences. 2019;4(4). https://doi.org/10.33889/IJMEMS.2019.4.4-073.

23. Liu, L., Peng, J.F., Guo, C.X., Yang, X.D., Li, H.G., \& Yang, G.P. Regulative effects of miR-150 on CYP3A4. Chinese Journal of Clinical Pharmacology and Therapeutics. 2018;23(07), 749-754.

24. Wu, M.L., Fan, Y., Yang, Y.Q., He, D., Yao, Z., \& Song, B. Dendrobium nobile polysaccharide improves symptoms of NAFLD rats by down-regulating CYP2E1 expression. Medical Journal of West China. 2020;32(04), 
505-509+514. https://doi.org/CNKI:SUN:XIBU.0.2020-04-011.

25. Yuan, J.H., Ge, K., Mu, J.H., Rong, J., Zhang, L., Wang, B., Wan, J.Y., \& Xia, G. Ferulic acid attenuated acetaminophen-induced hepatotoxicity though down-regulating the cytochrome P 2E1 and inhibiting toll-like receptor 4 signaling-mediated inflammation in mice. American journal of translational research. 2016;8(10), $4205-4214$.

26. Chen, K.G. Function and mechanism of CYP2E1/microRNA-378a-3p in acetaminophen and tripterygiumglycosides-induced liver injury. Shandong university. 2020.

27. Wang, X., Han, X., Wang, Y.F., \& Liu, Y. Compatible effects of vinegar-preparing Kansui and radix Glycyrrhizae preparata on CYP2E1 and CYP3A4 expressions in rat liver. Chinese Archives of Traditional Chinese Medicine. 2017;35(07), 1679-1683+1925. https://doi.org/ 10.13193/j.issn.1673-7717.2017.07.012.

28. Patton, A.L., Seely, K.A., Yarbrough, A.L., Fantegrossi, W., James, L.P., McCain, K.R., Fujiwara, R., Prather, P.L., Moran, J.H., \& Radominska, P.A. Altered metabolism of synthetic cannabinoid JWH-018 by human cytochrome P450 2C9 and variants. Biochemical and Biophysical Research Communications. 2018;498(3), 597-602. https://doi.org/10.1016/j.bbrc.2018.03.028.

29. Calvo, A.M., Zupelari, G.P., Dionísio, T.J., Brozoski, D.T., Faria, F.A., 
Santos, C.F. Efficacy of piroxicam for postoperative pain after lower third molar surgery associated with $\mathrm{CYP} 2 \mathrm{C} 8 * 3$ and CYP2C9. Journal of pain research. 2017;10, 1581-1589. https://doi.org/10.2147/JPR.S138147.

30. Wang, Q.L., Zou, Z.S. Association between cytochrome P450 gene polymorphism and drug-induced liver injury. Journal of Clinical Hepatology. 2020;36(05), 1150-1153. https://doi.org/CNKI:SUN:LCGD.0.2020-05-056.

31. Jing,X.Y., Peng, Y.R., Wang, X.M., \& Duan, J.A. Combined effect of Euphorbia kansui and Glycyrrhizauralensis on metabolism of Kansuinine A and Kansuinine B. Chinese Pharmacological Bulletin. $2015 ; 31(01)$

136-140. https://doi.org/10.3969/j.issn.1001-1978.2015.01.029.

32. Liu, H., \& Fan, X.S. Network pharmacology on interaction of effective or toxic components Kansui Radix and Glycyrrhizae Radix et rhizome. Chinese Journal of Experimental Traditional Medical Formulae. 2016;22(09), 186-192. https://doi.org/10.13422/j.cnki.syfjx.2016090186.

33. He, M.J., Lv, C.Z., Wang, B., Meng, X.L., \& Zhang, S.S. Preliminary investigation on processing mechanism of Kansui Radix by liquorice based on thermal analysis technology. China Journal of Chinese Materia Medica. $2018 ; 43(21)$ 
4255-4263. https://doi.org/10.19540/j.cnki.cjcmm.2018.0112.

34. Guo, M., Cui, N., \& Wang, W. Compatibility rule of Glycyrrhiza Radix et rhizome group in 18 incompatible pairs. Journal of Emergency in Traditional Chinese Medicine. 2018;27(12), 2254-2256. https://doi.org/CNKI:SUN:ZYJZ.0.2018-12-060.

35. Shen, J., Wang, J., Shang, E.X., Tang, Y.P., Kai, J., Cao, Y.J., Zhou, G.S., Tao, W.W., Kang, A., Su, S.L., Zhang, L., Qian, D.W., \& Duan, J.A. The dosage-toxicity-efficacy relationship of kansui and licorice in malignant pleural effusion rats based on factor analysis. Journal of ethnopharmacology. $2016 ; 186$ 251-256. https://doi.org/10.1016/j.jep.2016.04.012.

36. Juan S., Zong, J.P., Jun, K., An, K., Yu, P.T., Li, L.S., Gui, S.Z., Zhu, Z.H., Shang, E.X., Li, S.P., Cao, Y.J., Tao, W.W., Su, S.L., Zhang, L., Zhou, H.P., Qian, D.W., \& Duan, J.A. Comparative metabolomics analysis for the compatibility and incompatibility of kansui and licorice with different ratios by UHPLC-QTOF/MS and multivariate data analysis. Journal of Chromatography B. 2017;1057, 40-45. https://doi.org/10.1016/j.jchromb.2017.04.042.

37. Dong, W., Li, C.Y., Yang, M., \& Sun, H. Research progress on the compatibility of toxicity and attenuation of toxic herbs with Licorice. Journal of Tonghua Normal University. 2018;39(02), 12-17. https://doi.org/10.13877/j.cnki.cn22-1284.2018.02.004. 
38. Lin, Y. Investigation the compatibility between Euphrobia kansui and Glycyrrhiza based on the pathway of water metabolism regulation. Fujian university of traditional Chinese medicine. 2016.

39. Sun, Y.Y. The toxicity effect of Euphorbia kansui and Licorice with different proportion on rats' kidney. North China university of science and technology. 2015.

40. Zhang, J.M., Xu, W., Zhong, G.S., Guo, Y.S., Liu, H.Y., Ou, L.N., Zhao, T., Liu, J., \& Wang, S.R. Review on the experimental studies of suitable and contraindicant conditions of Chinese medicine antagonism compatibility kansui radix and glycyrrhiza. Global Chinese $\quad$ Medicine. 2015;8(09), 1053-1058. https://doi.org/CNKI:SUN:HQZY.0.2015-09-006. 
Figure Legends

FIGURE 1 Content of $\mathrm{KC}$ in each group

FIGURE 2 Content of glycyrrhetinic acid in each group

FIGURE 3 Content of glycyrrhizic acid in each group

FIGURE 4 Content of KC, glycyrrhizic acid, and glycyrrhetinic acid in each group

FIGURE 5 Content of 1-hydroxymidazolam, 4-hydroxytoluenesulfonylurea, and 6-hydroxychlorzoxazone in each group (A-I)

FIGURE 6 Content of 1-hydroxymidazolam in each group (A-I)

FIGURE 7 Content of 4-hydroxytoluenesulfonylurea in each group (A-I)

FIGURE 8 Content of 6-hydroxychlorzoxazone in each group (A-I) 
Figures
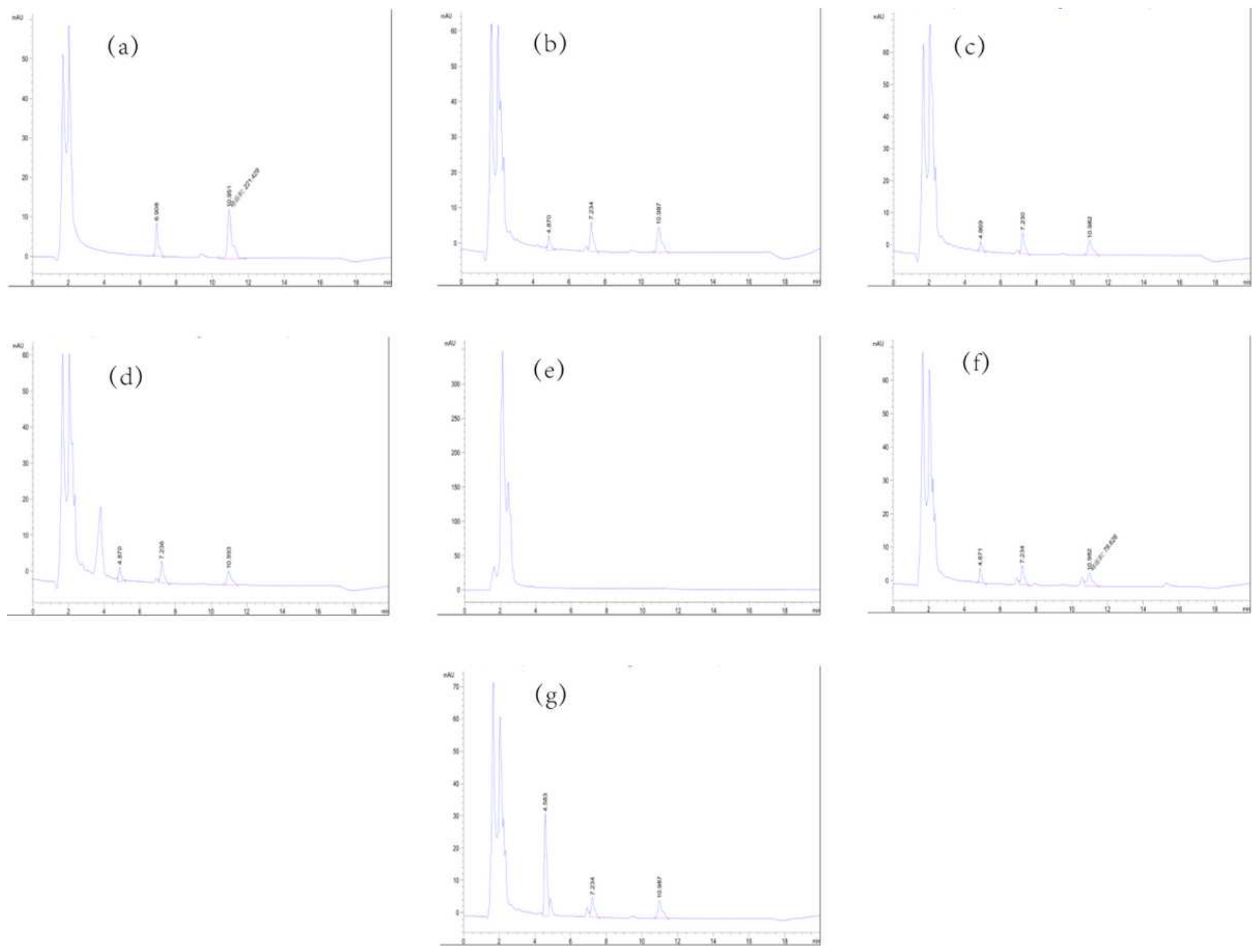

Figure 1

Content of $\mathrm{KC}$ in each group 

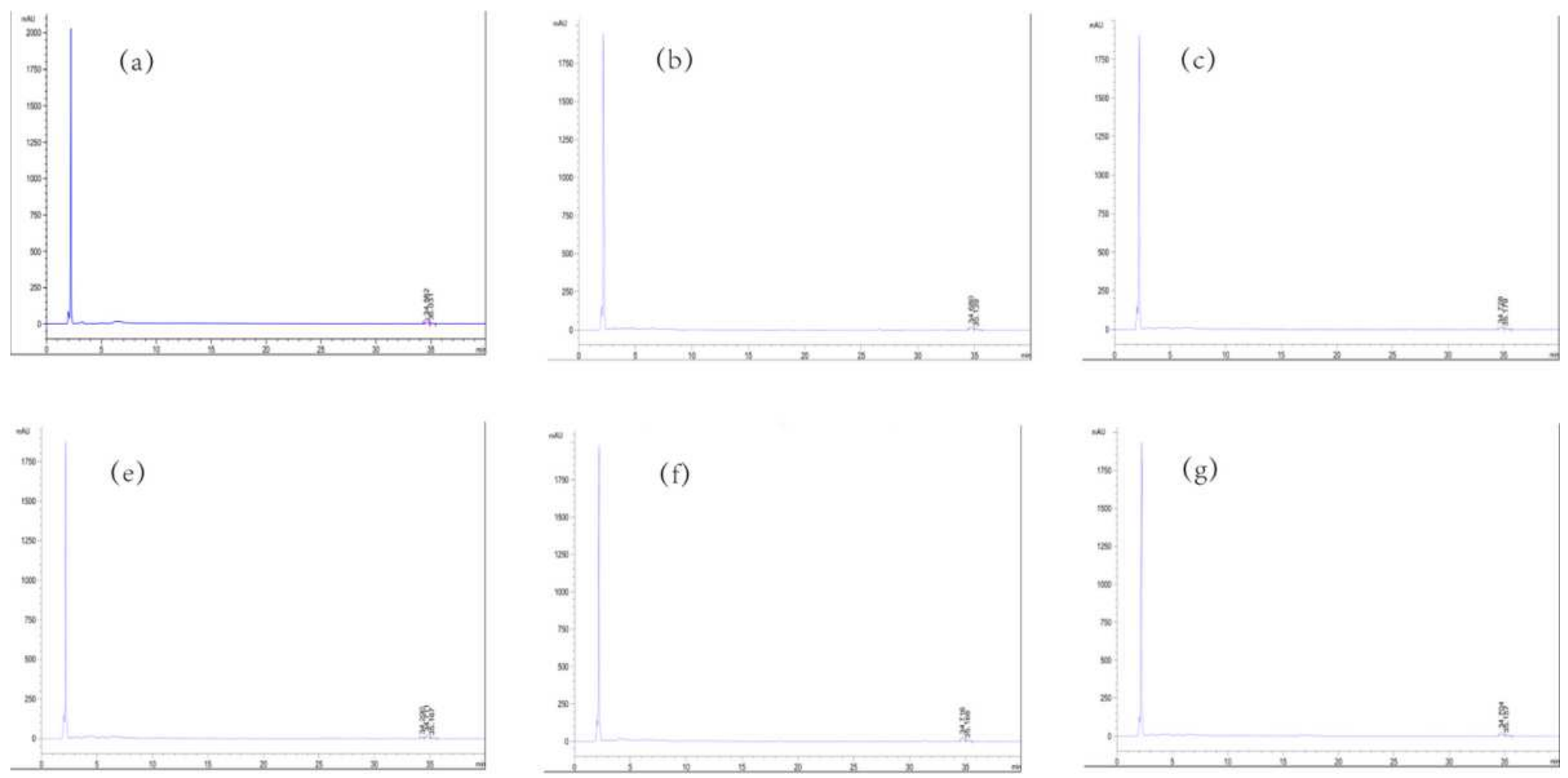

Figure 2

Content of glycyrrhetinic acid in each group
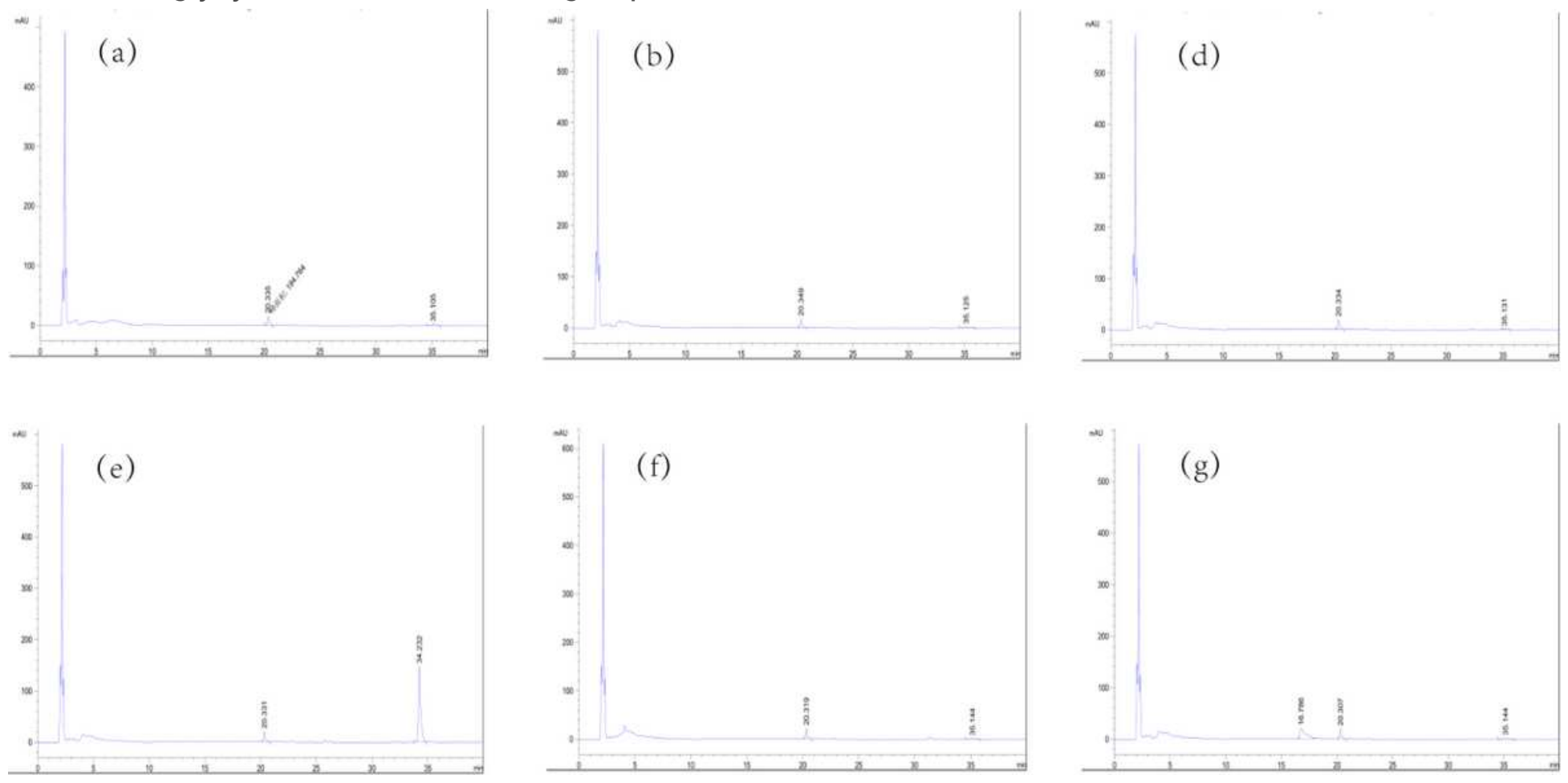

Figure 3

Content of glycyrrhizic acid in each group 


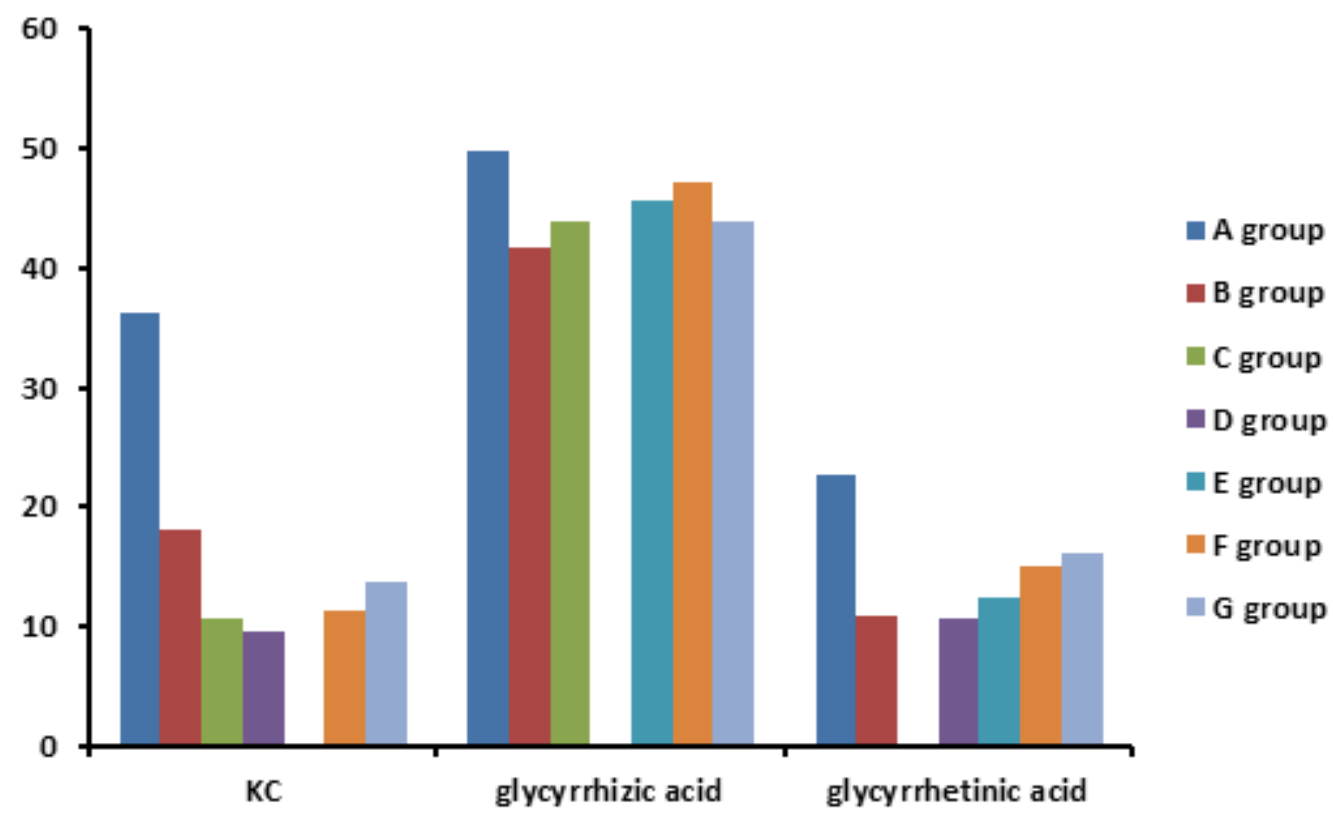

Figure 4

Content of KC, glycyrrhizic acid, and glycyrrhetinic acid in each group

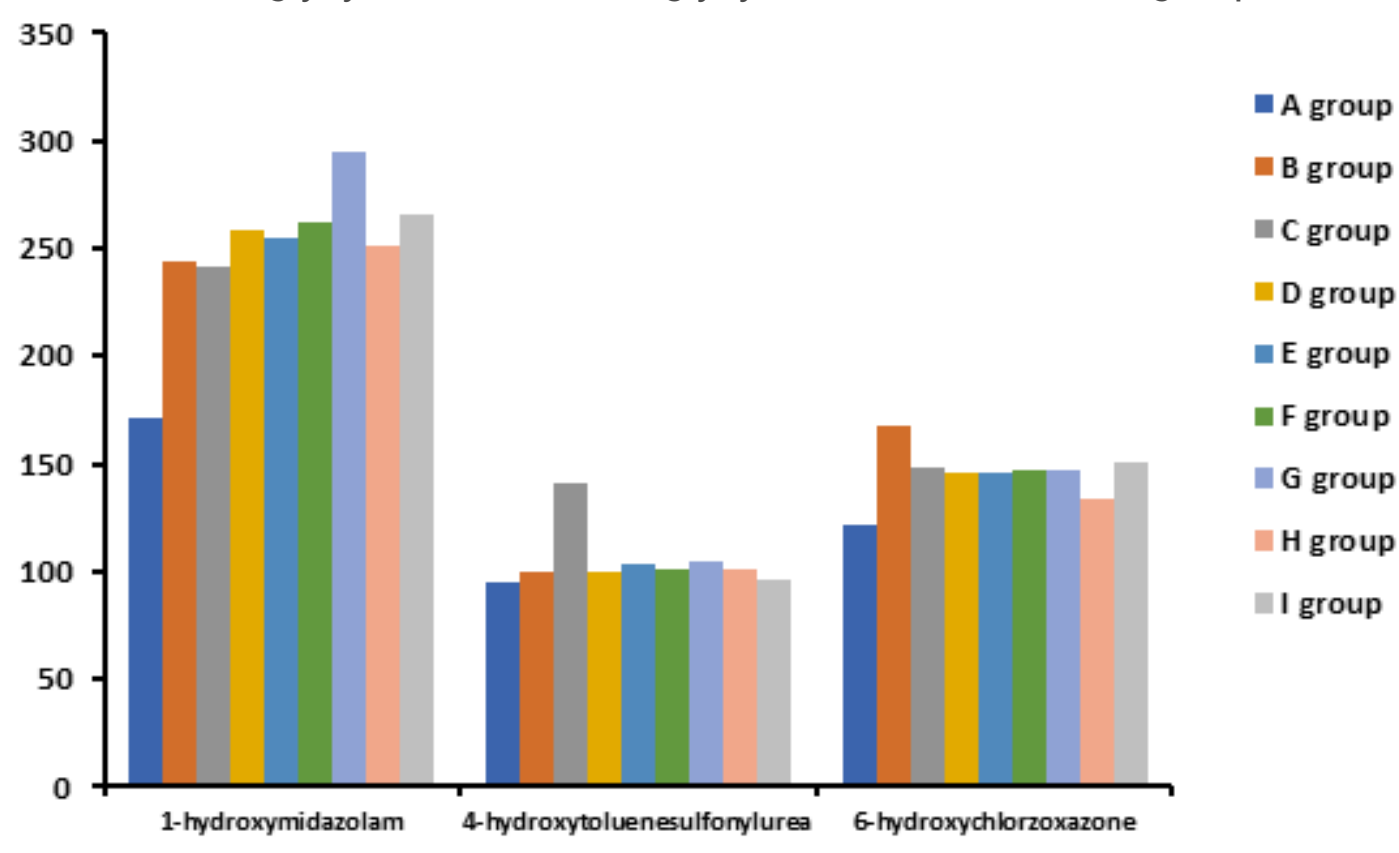

Figure 5

Content of 1-hydroxymidazolam, 4-hydroxytoluenesulfonylurea, and 6-hydroxychlorzoxazone in each group $(A-I)$ 

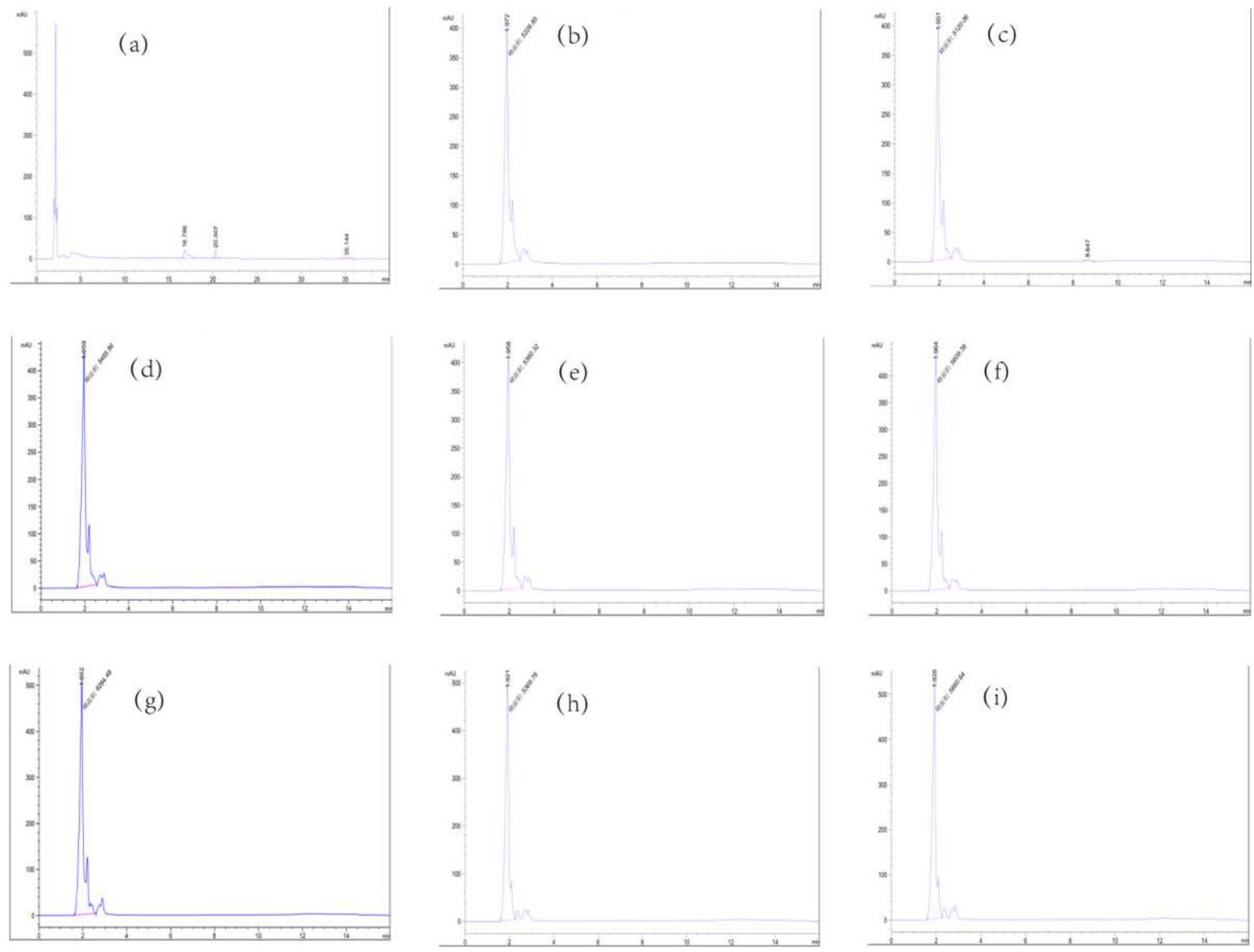

Figure 6

Content of 1-hydroxymidazolam in each group (A-I) 

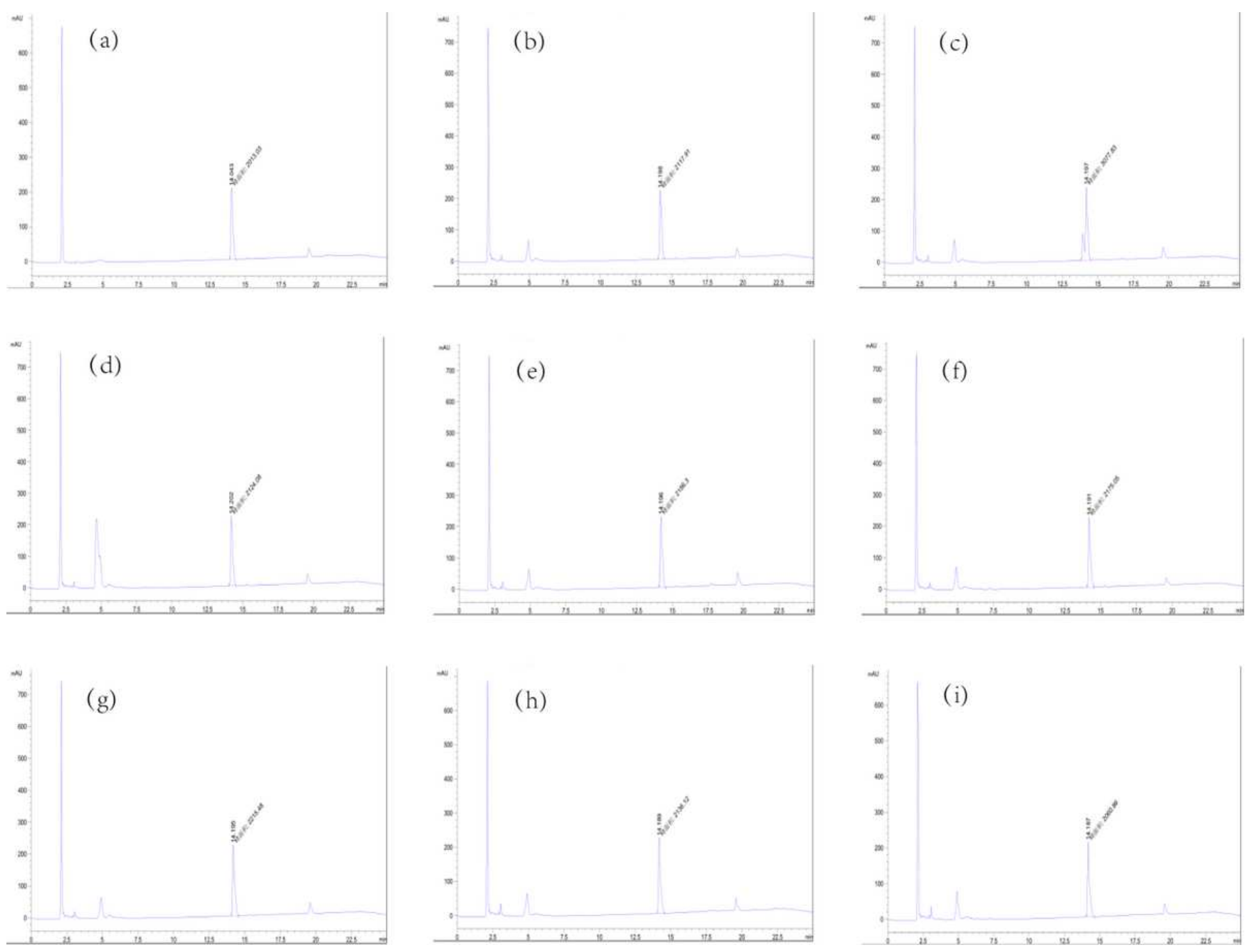

Figure 7

Content of 4-hydroxytoluenesulfonylurea in each group (A-I) 

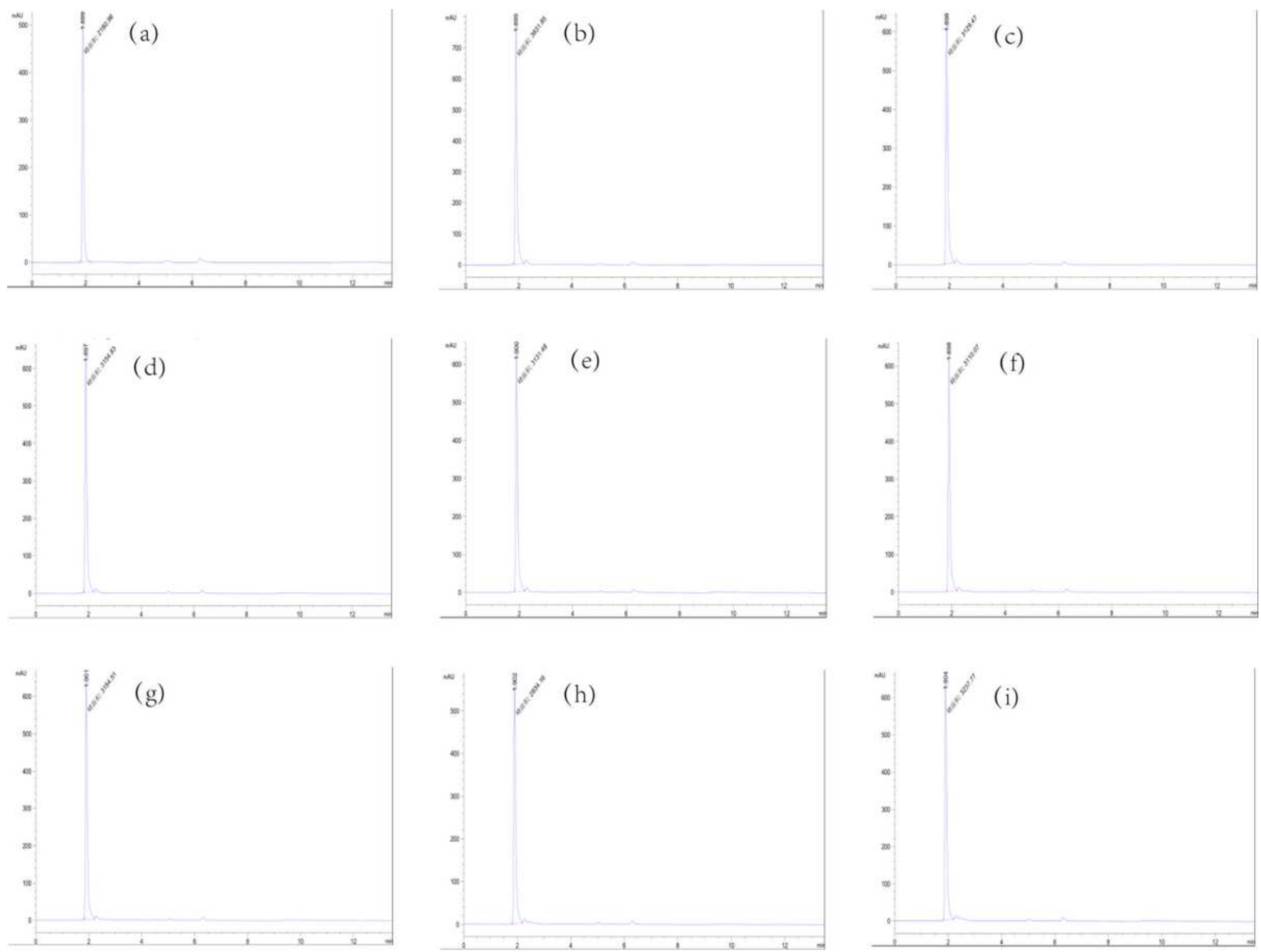

Figure 8

Content of 6-hydroxychlorzoxazone in each group (A-I) 